Revista de la red interuniversitaria de estudios sobre las literaturas rioplatenses contemporáneas en Francia

$10 \mid 2014$

El XIX en el XX

\title{
Nuevas lecturas críticas de Onetti después de Onetti
}

\author{
Julieta Viú
}

\section{OpenEdition}

Journals

Edición electrónica

URL: http://journals.openedition.org/lirico/1594

DOI: $10.4000 /$ lirico.1594

ISSN: 2262-8339

\section{Editor}

Réseau interuniversitaire d'étude des littératures contemporaines du Río de la Plata

\section{Referencia electrónica}

Julieta Viú, «Nuevas lecturas críticas de Onetti después de Onetti », Cuadernos LIRICO [En línea], 10 | 2014, Publicado el 15 marzo 2014, consultado el 22 septiembre 2020. URL : http:// journals.openedition.org/lirico/1594; DOI : https://doi.org/10.4000/lirico.1594

Este documento fue generado automáticamente el 22 septiembre 2020

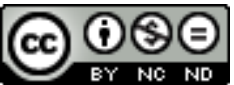

Cuadernos LIRICO está distribuido bajo una Licencia Creative Commons Atribución-NoComercialSinDerivar 4.0 Internacional. 


\section{Nuevas lecturas críticas de Onetti después de Onetti}

Julieta Viú

REFERENCIA

Basile, Teresa y Foffani, Enrique (comp.), Onetti fuera de sí, Buenos Aires, Katatay, 2013, $286 \mathrm{p}$. 
La literatura de Juan Carlos Onetti ha ingresado, en este último tiempo, en la vorágine de las reescrituras. La potencialidad de determinadas narrativas permite la proyección y la expansión hacia otras producciones. Onetti fuera de sí, publicado a principios del 2013 en la colección Memorias de la editorial Katatay, se ocupa de este fenómeno. El tratamiento del tema no se limita al campo literario ya que la propuesta crítica es analizar la narrativa onettiana en interacción con producciones de otros campos, más específicamente, en el escenario de la cultura latinoamericana. La compilación realizada por Teresa Basile y Enrique Foffani reúne una serie de estudios y abordajes críticos sobre el escritor uruguayo que provienen del Coloquio

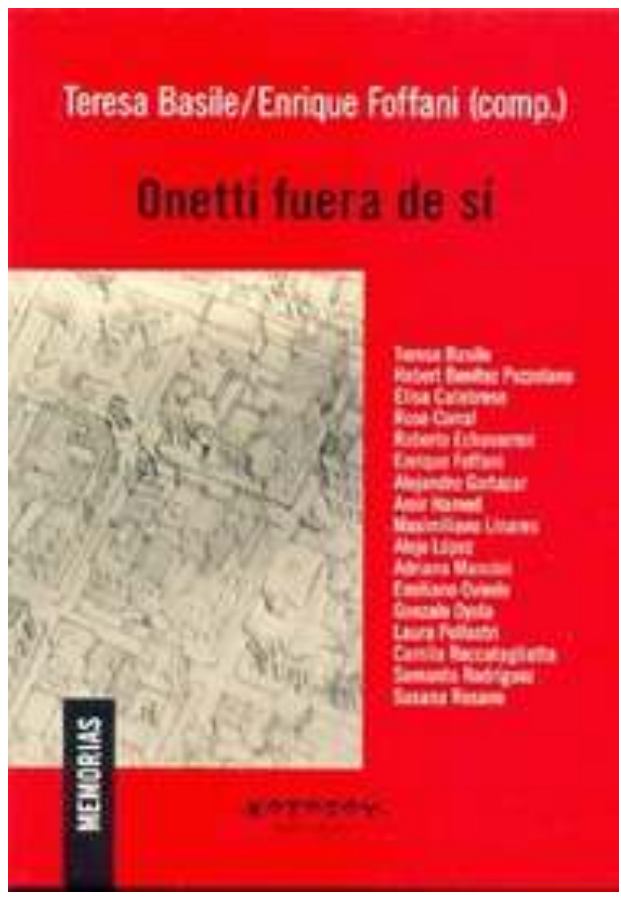
Internacional: La obra narrativa de Juan Carlos Onetti, realizado en noviembre del 2009 en la ciudad de Buenos Aires, y del Seminario de doctorado, codictado por ambos compiladores ese mismo año en la Universidad Nacional de La Plata. Además, el volumen cuenta con artículos escritos especialmente para esta publicación. El título resulta atractivo y es elocuente al mismo tiempo ya que logra condensar la situación en la que se encuentra la obra de Onetti. Su literatura verdaderamente fecunda es capaz de salir de sí misma. Nos encontramos con un Onetti desaforado, desbocado, ingobernable que es procesado y fagocitado por otros lenguajes y otras artes. De este modo, el título transmite la sensación arrolladora que suponen las proyecciones de una obra hacia otras literaturas $\mathrm{y}$, también, hacia obras fílmicas, artísticas y críticas. Como explican los compiladores, sólo Onetti fuera de Onetti es capaz de ingresar "en otras narrativas como las de Amir Hamed, Juan Villoro y Carlos Liscano, [...] en algunos films como el de Pablo Dotta y [en el] trazo minucioso y serpentino de Tunda Prada; porque ante su literatura los críticos comienzan a desplazarse hacia otras artes, otros saberes, otros discursos ... [...]" (11).

2 En el estudio introductorio, "Notas para entrar y salir de Onetti", Basile y Foffani construyen la historia de las reescrituras, que supone, al mismo tiempo, organizar una historia de las lecturas y de los abordajes teóricos desde los cuales se ha analizado la obra del escritor uruguayo. Este artículo sitúa el origen de la publicación en el Coloquio Internacional y en el Seminario pero, principalmente, es producto de una mirada atenta y minuciosa de lo que significó 2009. Significativo de la recepción crítica de la producción literaria de Onetti, ese año estructura la lectura de Basile y Foffani, quienes hacen foco en las operaciones críticas que tuvieron lugar en el centenario del nacimiento del escritor.El homenaje generó, entre otras cosas, la publicación de dos ediciones críticas fundamentales : el tercer tomo de las Obras completas por la editorial Galaxia Gutenberg y las Novelas cortas, por Archivos. Además, ese mismo año se publicó el epistolario, hasta ese entonces inédito, entre Onetti y Julio E. Payró a cargo de Hugo Verani. En el campo de la crítica literaria, se destacó la reedición de los libros Onetti. Los 
procesos de construcción del relato de Josefina Ludmer y Onetti : el ritual de la impostura de Hugo Verani ; y, en el campo artístico, tuvo lugar el estreno de la película Jamás leí a Onetti de Pablo Dotta. Es necesario destacar entonces que el ensayo de Basile y Foffani, si bien reconstruye el clima y la escena que se generó en torno a la conmemoración del nacimiento, logra tomar distancia de ese complejo fenómeno editorial, artístico y crítico para desmontar las operaciones de lecturas que se articularon allí.

3 La compilación está organizada en seis apartados. En "Literatura y las otras artes", se abordan cruces y tensiones entre distintas disciplinas que se manifiestan en la escritura de Onetti. En primer lugar, Rose Corral analiza, a partir de la publicación de la correspondencia del escritor con Payró, el vínculo que une la escritura de Onetti con el teatro, género con el que el uruguayo tiene contacto en sus años iniciales antes de entrar a trabajar al periódico Marcha. Se focaliza en lo teatral como un recurso que le permite al escritor experimentar con las posibilidades expresivas en la ficción. En segundo lugar, Roberto Echavarren escribe "El caballero de la rosa", donde interroga la construcción y la desconstrucción del género erótico a partir de la composición de algunos personajes onettianos. El crítico encuentra vínculos entre los personajes de Onetti y los del escritor inglés D. H. Lawrence. En tercer lugar, al reflexionar sobre la relación entre la escritura de La vida breve y la imagen, Laura Pollastri desarrolla una interpretación innovadora : la materia prima de la ficción onettiana, en este caso, es el cuadro Wherefore Now Ariseth the Illusion of a Third Dimension de Ivan Albright. Este descubrimiento permite advertir hasta qué punto La vida breve "es un enorme laboratorio narrativo que transubstancia prácticas provenientes de otros registros estéticos y de otros modos de representación" (64). En cuarto lugar, el guionista y crítico de cine Emiliano Oviedo aborda la tensión con el realismo en esa misma novela y sostiene que si bien en esta obra sobresale el "mecanismo analítico y revisor de la ficción realista" (69), es posible analizar, en el capítulo "Naturaleza muerta", el influjo de la estética naturalista.

4 El segundo apartado del libro, "El astillero de Onetti : entre la alegoría y la realidad", compuesto por dos artículos que abordan dicha novela, se abre con un análisis de Teresa Basile, quien asume el desafío de contradecir la interpretación del propio escritor, volcada en numerosas entrevistas, al sostener que el dispositivo que predomina en la novela es la alegoría. Ésta presenta dos características centrales : en primer lugar, la "duplicidad del significado" que se evidencia en el vínculo entre el relato de la razón instrumental y el discurso de la razón emancipatoria. En segundo lugar, la alegoría implica la presencia de una "metáfora extendida". En sintonía con este análisis, Hebert Benítez Pezzolano escribe sobre el tema de la farsa como interpretación o lectura metafórica de El astillero. La farsa es la puesta en ficción de una mentira que siempre supone una verdad oculta. Desde esta perspectiva, la novela cobra una vigencia crítica insospechada si es leída a la luz de la situación actual de las democracias latinoamericanas en la época del capitalismo globalizado, afirma el autor.

5 El tercer apartado del libro, "Las escrituras de Onetti : las sagas de un viejo narrador", contiene dos reveladores artículos. En el primero, Enrique Foffani analiza la creación/ invención de territorios literarios dentro del vasto campo de las sagas narrativas. Allí, el crítico establece un vínculo entre la escritura de Onetti y la de Juan José Saer en tanto ambas comparten la autonomía del territorio literario. La pregunta por lo real y el cuestionamiento de la categoría de ficción se hallarían en el centro de estas narrativas. El segundo artículo, escrito por Adriana Mancini, es un análisis que se focaliza en los 
avatares de la vejez en la narrativa de Onetti. La investigadora sostiene que la obra del escritor permite reflexionar sobre este tema por la manera de construir los personajes, el tratamiento particular que realiza del tiempo y, entre otras cuestiones, por la proximidad con la muerte.

6 El cuarto apartado, "Onetti y los mitos populares", comienza con dos escritos excéntricos del escritor y músico uruguayo Amir Hamed. El primer texto toma del tango no sólo el título -“Adiós, muchachos"- sino también uno de sus grandes temas : el ansia de juventud y la inevitabilidad de la vejez. Con una prosa poética, este breve texto plantea la tensión, muy marcada en la sociedad actual, entre ser joven y envejecer. En consonancia con la preocupación de Mancini, vuelve a hacerse presente aquí el tratamiento del tiempo, la muerte y la vejez. El segundo texto aborda el cuento "Bienvenido, Bob" a partir de una crónica de Alfredo Zitarrosa. Con un tono ensayístico, Hamed analiza cómo por medio de la técnica del esperpento, el escritor muestra el aspecto negativo del futuro. Trabaja la relación entre los personajes adultos, quienes son capaces de percibir un porvenir de desengaños, y los jóvenes, obstinados en desoír a aquellos. A continuación, dos artículos reflexionan sobre Ella, cuento que permaneció inédito hasta 1994. Por un lado, Susana Rosano, en "Onetti y su relato sobre la muerte de Evita", analiza aspectos narrativos del cuento en el horizonte de lo que llama "la escritura cadavérica", esto es, una serie de textos de distintos autores en torno a las representaciones de la muerte de Eva Perón. Establece vínculos con el cuento "El simulacro" de Jorge Luís Borges y "La señora muerta" de David Viñas y los poemas "El cadáver" y "El cadáver de la Nación" de Néstor Perlongher. Por otro lado, Gonzalo Oyola, en "A las veinte y veinticinco entró en la inmortalidad. Notas sobre "Ella" de Juan Carlos Onetti", otorga un lugar fundante a este cuento en la serie textual BorgesViñas-Walsh al sostener que Ella inaugura temas y motivos de la literatura sobre Eva Perón : "la elisión del nombre (Viñas y Walsh), el cadáver como cuerpo político (Walsh) y los funerales como escenario (Viñas, Borges)" (184).

7 El quinto apartado, "Reflexiones sobre la poética onettiana", se abre con un artículo de Elisa Calabrese sobre la ética literaria que se basa en el valor humano y social que el escritor le otorga a la literatura alejándola de toda concepción lúdica. Sostiene que la concepción de la escritura de Onetti se basa en la idea romántica del arte como destino. Esa exigencia de una moral literaria repercute, por ejemplo, en la construcción de personajes como el fracasado o el indiferente moral con una fuerte influencia de Arlt, y en la creación de una Santa María cuya realidad no depende de la verosimilitud tradicional sino que se presenta como una imaginación totalizante. Alejandro Gortázar aborda las representaciones de lo étnico-racial y plantea la hipótesis de una Santa María mestiza. El crítico sostiene que la ruptura de la estética realista es acompañada por una ruptura con el criterio de representatividad propio de las novelas decimonónicas y del regionalismo. El apartado se cierra con un relevante ensayo crítico de Maximiliano Linares, donde se analiza el arte de narrar onettiano con especial énfasis en las categorías de narrador y de personaje. La "posta de narradores", categoría crítica que cifra esta lectura, implica un encadenamiento de versiones -que como sostiene Linares puede implicar distorsiones-, un traspaso de información entre los narradores (muchas veces personajes). El relevo de las versiones conforma el sistema narrativo que Onetti llevará al paroxismo en Para una tumba sin nombre.

"Onetti y la máquina de hacer relatos", el último apartado, está compuesto por tres artículos que ahondan en distintos mecanismos narrativos. Haciendo énfasis en las 
estrategias ficcionales, Alejo López analiza el cuento "El álbum", Samanta Rodríguez estudia "Tan triste como ella" y Camila Roccatagliata aborda la nouvelle "Historia del caballero de la rosa y de la Virgen encinta que vino de Liliput".

9 Los trabajos reunidos en esta compilación manifiestan de manera más o menos evidente un corrimiento de límites en relación a las perspectivas y a los abordajes de análisis de la obra literaria. El compromiso que este libro asume y logra realizar es descanonizar las lecturas sobre el escritor uruguayo. Los límites están continuamente puestos en cuestión y, por ello, es posible hablar de un Onetti en otras narrativas, un Onetti después de Onetti. Los estudios críticos de Pollastri, Foffani, Basile, Linares y Calabrese, por nombrar sólo algunos, abordan esta obra dejando de lado el canon y las lecturas instituidas al proponer nuevos modos de ingresar a la obra onettiana. Hoy, es posible, como lúcidamente plantean Basile y Foffani, entrar y salir de Onetti.

\section{AUTORES}

JULIETA VIÚ

UNR-CONICET 